\title{
Safety and Efficacy of Dapoxetine in the Treatment of Premature Ejaculation: A Double-Blind, Placebo-Controlled, Fixed-Dose, Randomized Study
}

\author{
Mohammad R Safarinejad*, I \\ 'Urology and Nephrology Research Center, Shaheed Beheshti University of Medical Sciences, Tehran, Iran
}

The aim of the study was to evaluate the efficacy and safety of a selective serotonin reuptake inhibitor ss, l) a dapoxetine in delaying ejaculation in patients with premature ejaculation (PE). A total of 212 potent men with PE were ra omly ass sned to receive $30 \mathrm{mg}$ orally dapoxetine (group I, $N=106$ ) twice daily or similar regimen of placebo (group 2, N=105) dun a I2-week period for each agent. Pretreatment evaluation included history and physical examination, geometric mear In primary outcome measure), and International Index of Erectile Function (IIEF). The eill v v cus treatments was assessed every 2 weeks during treatment, at the end of study, and in 3-month follow-up after cessation of t tment. We measured geometric mean IELT. Thus, the IELT values were logarithmically transformed before statistical analys, the res alts are reported as fold increases from baseline with associated $95 \%$ confidence intervals $(\mathrm{Cl})$. The independent sample two tail cas cst was used to compare the IELTs. At the end of 12 -week treatment, the dapoxetine group had a 2.9- $(95 \% \mathrm{Cl}, 1.84-4.16)$ fold increase of the geometric mean IELT, while after placebo the geometric mean IELT did not increase significantly $(1.4-f(1)$ ase; 95.6 Cl, 0.84-I.63) $(p=0.00 \mathrm{I})$. The mean weekly intercourse episodes increased from pretreatment values of $1.16,1.14$ t 2.2 and 1.4 , for dapoxetine and placebo, respectively $(p=0.04)$. Baseline mean intercourse satisfaction domain values $f \| E F, ?$ anc 11 , reached to 16 and 10 at the 12 -week treatment in groups I and 2, respectively $(p=0.04)$. At the end of 3-mon foll $w$-up ilod, the geometric mean IELT in dapoxetine and placebo group demonstrated 1.4- $(95 \% \mathrm{Cl}, 0.66-1.46)$ and I.3- ( $, \mathrm{Cl},(7 \%-1.63)$ fold increase, respectively $(p=0.1)$. Three-month intercourse satisfaction domain value of IIEF was II in $\sigma$ oup I an 0 , ngroup $2(p=0.1)$. Mean number of adverse events was 19 for dapoxetine and 7 for placebo $(p=0.02$ ). Dapoxet ie moderately better results in terms of IELT and intercourse satisfaction vs placebo without long-term benefit for the patien fter it is ithdrawn. Further studies are necessary to draw final conclusions on the efficacy of this drug in PE.

Neuropsychopharmacology (2008) 33, 1259- , 55; doi: J. I038/sj.npp. I30 I500; published online I I July 2007

Keywords: premature ejaculation; th ment; dapoxetine; serotonin; sexual dysfunction

\section{INTRODUCTION}

There is limited ntorma $n$ concerning the extent of premature ejar latio $n(P E)$ in general population. In a random survey 1511 men in the United States, about one-third sider sat they had ejaculated prematurely over th nas vear (Laumann et al, 1999). However, the proportion hat perceived their condition as problematic was not stat. Data from the National Health and Social Life Survey have revealed a prevalence of $21 \%$ in men aged 18-59 years in the United States (Fisher, 1986). In general,

\footnotetext{
*Correspondence: Dr MR Safarinejad, Urology and Nephrology Research Center, Shaheed Beheshti University of Medical Sciences, PO Box 19395-|849, Tehran 1956989333, Iran, Tel: +9821 2245 4499, Fax: +9821 2245 6845, E-mail: safarinejad@urologist.md Received 2 November 2006; revised 27 April 2007; accepted 5 June 2007
}

however, the prevalence of $\mathrm{PE}$ is reported as being between 22 and $38 \%$ of adult male population (Laumann et al, 1999; Spector and Carey, 1990). The World Health Organization (WHO) includes the right to sexual health among its fundamental rights for an individual. There should be 'a freedom from organic disorders, disease, and deficiencies that interfere with sexual and reproductive freedom'. PE has been associated with erosion of sexual self-confidence (Symonds et al, 2003) and low sexual satisfaction in men and their female partners (Byers and Grenier, 2003). Ejaculation is affected by numerous mechanisms. Among these, the most accepted and, maybe, the most important one is central serotonin (5-hydroxytryptamine, 5-HT) level. The inhibitory effect of serotonin on libido, ejaculation, and orgasms is well documented and has been attributed to a serotonin-induced decrease in dopamine (a neurotransmitterenhancing sexual function) level in the central nervous system (Remy, 1986; Baldesarani and Mars, 2003). Selective 
serotonin reuptake inhibitors (SSRIs: paroxetine, fluoxetine, sertraline, and citalopram) are reported to be effective for treating PE (Waldinger et al, 2004a; Safarinejad and Hosseini, 2006), but they were not developed to treat PE. Probable mechanism of these drugs is the enhancement of net serotonergic transmission by blocking the presynaptic 5-HT (serotonin) uptake site (Waldinger et al, 1998a). A member of the well-known SSRI class of compounds, dapoxetine would become the first oral pharmacologic product indicated for the treatment of $\mathrm{PE}$, but at the end of 2005 has not been approved by the FDA as an oral drug for the treatment of PE. Dapoxetine $((+)-(\mathrm{S})-N, N$-dimethyl $(\alpha)$-[2(1-naphthalenyloxy) ethyl]-benzenemethanamine hydrochloride) is an SSRI. Dapoxetine is a fast-acting inhibitor of the serotonin reuptake (Feret, 2005). Dapoxetine is rapidly absorbed after oral administration with a peak plasma concentration occurring between 1.4 and $2.0 \mathrm{~h}$. This is followed by a rapid decline in plasma concentration, to about $5 \%$ of peak concentration at $24 \mathrm{~h}$. Both, the area under the curve (AUC) and $C_{\text {max }}$, increase proportionately with doses up to $100 \mathrm{mg}$. The mean initial half-life of dapoxetine after a single dose is $0.5-0.8 \mathrm{~h}$, and this decreases slightly to $0.4-0.6 \mathrm{~h}$ after multiple doses for 6 days. The terminal half-life of dapoxetine is $15-19 \mathrm{~h}$ after a single dose and 20-24 after multiple doses (Dresser et al, 2004).

Results from placebo-controlled, randomized, multicenter phase-3 trials have demonstrated that men with PE receiving dapoxetine 30 or $60 \mathrm{mg}$ experienced increased intravaginal ejaculatory latency and higher levels of contre? over ejaculation and satisfaction with sexual intercous (Pryor et al, 2006). In this study, the dose-effect rel ${ }^{1}$ itions were not determined, and the overall dose effect vas ot reported. One should take the log mean in tra inal ejaculatory latency time (IELT) or the me an IEL 0 compare treatment effects. By comparing the ean ILLT values, as the authors have done, there is considt le risk that dapoxetine seems to induce a fa stronger ejaculation delay than actually happens.

In all published studies, treatment a slow-up times have been only weeks, and th studies have been concentrated mainly on short-t r 1 e ects. Although the therapeutic effect of a dras seen within weeks, alleviation of problem for a mv lor ror tine is required. In some reports, after the en af th apy, the PE recurs in as much as $90 \%$ of patients rink et, 1996). We need a safe and effective drug I. unc a specifically for the treatment of $\mathrm{PE}$, especially it induct long-term benefit for the patient after it is throun. In this study we compared dapoxetine (a fast-actin $\mathrm{SSR}^{\mathrm{T}}$, with placebo.

\section{MA' TIALS AND METHODS \\ Study Design}

From February 2004 to March 2006212 potent married men with $\mathrm{PE}$ entered the study (mean age 36 years, range $20-55$ ). $\mathrm{PE}$ was defined as an IELT of less than 2 min that occurred in more than $90 \%$ of intercourses. The IELT was the time between the start of vaginal insertion and the start of intravaginal ejaculation (Waldinger et al, 1994). All patients gave their written informed consent to participate in the study after procedures and possible side effects were explained to them. The study was conducted in accordance with the Declaration of Helsinki and was approved by the local Medical Ethical Committee. At the first visit, patients and wives were interviewed individually by the author and were requested for an independent estimation of the IELT. A stopwatch and instructions on how to measure the IELT were also provided. The patient had to be in a stable relationship with his wife for at least the previous 6 months and possible sexual intercourse equal or greater than 1 per week. Couples were also instructed not to $\mathrm{u}$ condoms or topical anesthetic cream, not to pause dur' $g$ in 'ercourse or to have interrupted intromission. Further. ce, th $-y$ were requested if intercourse took place more th. once in a single session, only the first intercu se was measured.

\section{Evaluations}

All patients underwent medical and sexual misto physical examination, and structured intervi diagnos $C$ of mental and physical disorders, IELT, and lf-administration of International Index of Eres... Functio (IIEF) (Rosen et al, 1997). To be able to ex de arganic sexual dysfunction, fasting blood glucose lever, rrint analysis, complete blood count, sex horm nes, and colactin levels were measured. MearesStame aras also performed to exclude genital tract infectic . Prctreatment IELT was measured during a 4-week baseline neriod, during which patients were requested to verience coitus at least four times. All patients were asked to indicate their sexual satisfaction on a scale of $0-5$ as p oposed by Kim and Paick (1999), with 0 being extremely dissatisfied and 5 extremely satisfied. Pretreatment frequency of sexual intercourse was the mean number of attempts per week during the previous 2 months.

\section{Inclusion/Exclusion Criteria}

Only patients without any obvious organic cause of PE and possible sexual intercourse equal to or greater than 1 per week were included. Excluded were those with erectile dysfunction according to IIEF; an organic cause of PE including anatomical abnormalities, genital infection, and neurological disorder; low libido; chronic depression, psychiatric, or physical illness; alcohol, drug, or substance abuse; organic illness causing limitation in SSRI use; use of psychotropic and antidepressant medication; and serious relationship problems. Patients meeting study criteria had their medical and sexual histories and demographic information recorded.

\section{Medical Treatment}

Each eligible patient was given a randomization number using an interactive voice response system, which followed a randomization table generated by the method of random permuted blocks (Fleiss, 1986). At baseline (week 0), the patients were randomly assigned to take $30 \mathrm{mg}$ dapoxetine orally twice daily (every $12 \mathrm{~h}$ ) (group 1), or a similar regimen of placebo (group 2) during the 12-week treatment period. The placebo was a starch compound with the same color and size of dapoxetine. All of the men were asked not to consume alcoholic drinks within $6 \mathrm{~h}$ of sexual activity. 
Treatment was administered in a randomized sequence that remained unknown to the patient and to the physician. None of the patients underwent formal psychosexual counseling. Persons who were geographically and operationally independent from the study investigator did the randomization of the study. Patients were given a diary to record the frequency of coitus and adverse drug-related effects.

\section{Outcome Measures}

Patients were screened on week -4 . Baseline measurements were obtained on day -1 , and efficacy assessments were made every 2 weeks after the initial dose of dapoxetine on day 1 , at the end of 12-week treatment period, and 3 months after the cessation of treatment. For the analysis of efficacy and safety, all patients were assessed in each visit by the author evaluating changes in IELT (primary outcome measure), mean intercourse satisfaction domain, mean weekly coitus episodes (secondary outcome measures), and adverse drug effects. Patients and their wives were interviewed separately.

\section{Statistical Analysis}

The study sample size of 212 patients (106 per group) was powered for a difference of approximately 1 standard deviation (SD) between the dapoxetine and placebo group with a statistical power of $85 \%(\beta=0.15)$ and assuming an overall $10 \%$ dropout rate. As the IELT in individual patients usually follows a skewed distribution, we measurer geometric mean IELT instead of mean IELT. Thus, the IF T values were logarithmically transformed before stat tica analysis, and the results are reported as fold incre? from baseline with associated $95 \%$ confidence interval (C. The independent sample two-tailed $t$-test was us ${ }^{-1} \rightarrow \operatorname{com}_{\mathrm{r}} \mathrm{e}$ the geometric mean IELTs and frequenc of coitus by dapoxetine and placebo. Comparison of se al sati faction rates of patients and their wives and co ison of the incidence of side effects were tes $t$, ing the $\chi^{2}$-test. A $p$ value less than 0.05 was col sider $d$ statistically significant. Statistical analys as pe formed using the computer statistical packag- PS 110 (SPSS, Chicago, IL) and SAS/6.4 (SAS Instity co Cal, NC).

\section{RESULTS}

\section{Patient Disposs a/De 1ographics}

All patier is $n$ re see with their wives and were interviewed about th activity and the patient's ejaculation function. T re were no statistical differences in IELT, IIEF, and mean cotus attempts per week in the two groups (Table 1). A total of 212 patients were recruited, but only $189(89 \%)$ completed the whole randomized trial study (93 of 106 in the dapoxetine group and 96 of 106 in the placebo group) (Figure 1). Mean patient age was 35.7 years (range 21-54) in group 1 and 36.3 years (range 19-56) in group 2 ( $p=0.08$ not significant) (Table 1$)$. Twenty-three patients (10.9\%) did not complete the study: seven because of a lack of effects (two in the dapoxetine group and five in the placebo group), six because of adverse effects (dapoxetine
Table I Patient Characteristics

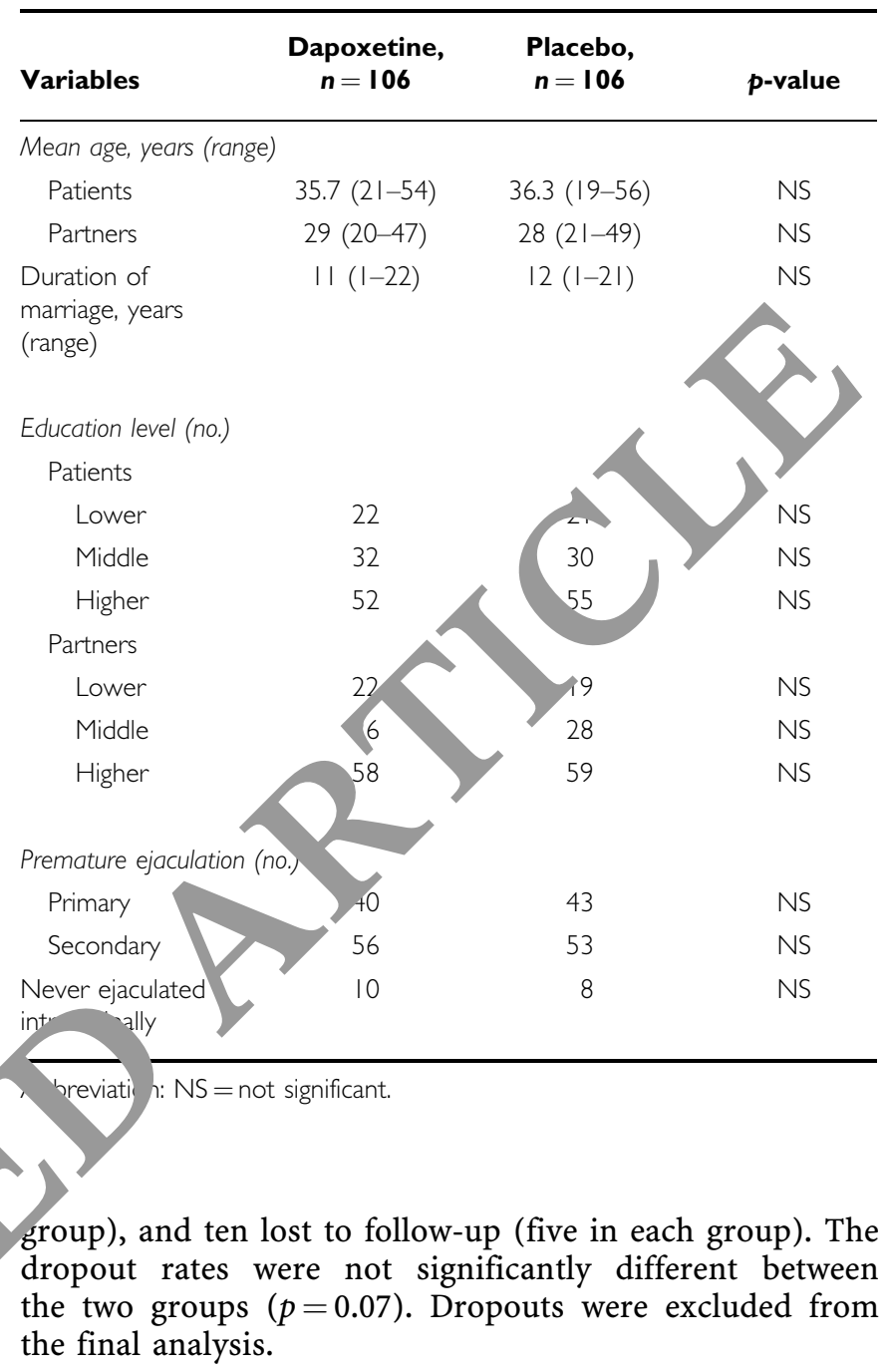

\section{Efficacy of Dapoxetine}

After 12 weeks of treatment, patients receiving dapoxetine demonstrated significantly improved IELT compared to those receiving placebo. The geometric mean IELT was moderately increased (2.9-fold; 95\% CI: 1.84-4.16) in the dapoxetine group, compared to only a gradual and mild increase in the placebo group (1.4-fold increase; $95 \% \mathrm{CI}$ : $0.84-1.63)(p=0.001)$ (Tables 2 and 3$)$. The mean pretreatment weekly intercourse episodes were 1.16 per week for dapoxetine compared to 1.14 for placebo. Dapoxetine demonstrated superiority in increasing mean pretreatment coitus frequency. The mean intercourse frequency at 12-week treatment was 2.2 and 1.4 for dapoxetine and placebo, respectively $(p=0.04)$. Baseline and 12 -week mean intercourse satisfaction domain values of the IIEF were 12, 11 and 16, 10 in groups 1 and 2, respectively. Dapoxetine group reported significantly greater intercourse satisfaction than those in placebo group $(p=0.04)$ (Table 4$)$. Before treatment, 18 of the 189 patients reported never having experienced intravaginal ejaculation. Intravaginal ejaculation was achieved by 7 of the 10 patients (mean age 28.5 years) who had never achieved it at the end of the treatment with dapoxetine. Intravaginal ejaculation was not achieved 
in eight patients (mean age 27.3 years) with placebo. Data analysis did not show any statistically significant difference in men with primary and secondary PE in terms of average baseline or 3-month geometric mean IELT. Similarly, data did not show significant differences in men with primary and secondary PE regarding IELT, IIEF domain, mean weekly coitus episodes, and adverse effects profiles.

In 3-month follow-up of treatment, geometric mean IELT, mean weekly intercourse episodes, and mean intercourse satisfaction domain values of the IIEF did not differ significantly between two treatment groups. At the end of 3 -month follow-up period, the geometric mean IELT in dapoxetine and placebo group demonstrated 1.4 (95\% CI; 066-1.4) and 1.3 (95\% CI: 0.77-1.63) fold increase, respectively $(p=0.1)$. At 3 -month follow-up, the mean intercourse frequency was 1.21 per week for dapoxetine compared to
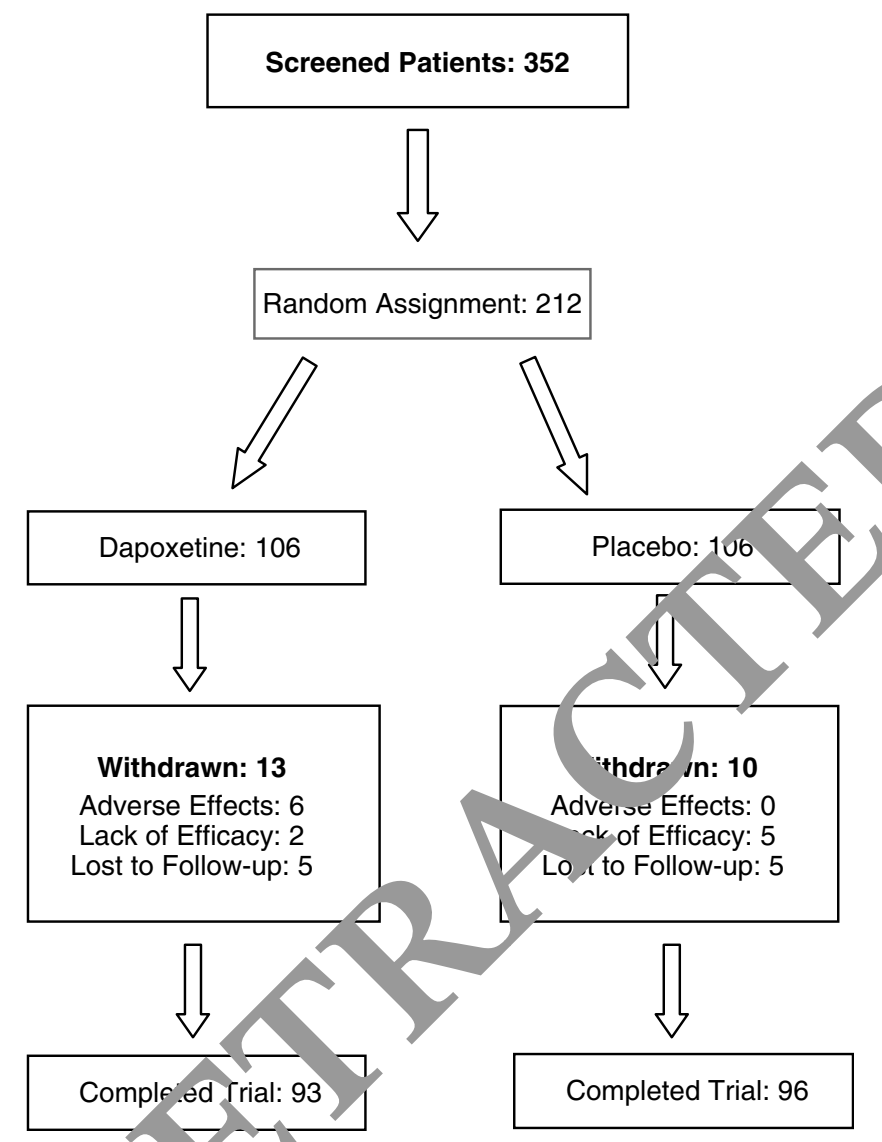

Figure

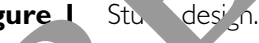

Table 4 íold Increase in Geometric Mean IELT

\begin{tabular}{|c|c|c|c|c|c|}
\hline \multirow[b]{2}{*}{ Group } & \multicolumn{2}{|c|}{ I 2-week } & \multicolumn{2}{|c|}{ 3-month follow-up } & \multirow[b]{2}{*}{$p$-value } \\
\hline & $\begin{array}{c}\text { Fold } \\
\text { increase }\end{array}$ & $95 \% \mathrm{Cl}$ & $\begin{array}{c}\text { Fold } \\
\text { increase }\end{array}$ & $95 \% \mathrm{Cl}$ & \\
\hline Dapoxetine & 2.9 & $1.84-4.16$ & 1.4 & $0.66-1.46$ & 0.001 \\
\hline Placebo & 1.4 & $0.84-1.63$ & 1.3 & $0.77-1.63$ & 0.1 \\
\hline
\end{tabular}

Abbreviation: IELT, intravaginal ejaculatory latency time.
1.19 per week for placebo $(p=0.1)$. The mean intercourse satisfaction domain values of the IIEF at 3-month follow-up were 11 and 10 for dapoxetine and placebo, respectively $(p=0.1)$ (Table 4). Erectile dysfunction was not noted with dapoxetine but was noted with placebo in two patients.

Anejaculation did not occur in our patients. Data analysis did not show significant differences in men with primary and secondary PE regarding IELT, IIEF domain, mean weekly coitus episodes, and adverse-effect profiles.

\section{Safety}

More adverse effects were assoc "ted with dapoxetine treatment $(p=0.02)$ (Table 5). Ninet $(20.4 \%)$ dapoxetine and seven $(7.3 \%)$ placebo ratients ited treatmentrelated adverse events; the $\mathrm{m}$ st common in the dapoxetine group were nausea $(5,5 \%)$, iarrh a $(5,5.4 \%)$, insomnia $(4,4.3 \%)$, headache $(4.4 . \%)$, anu dizziness $(3,3.2 \%)$. Six patients were dropp d out or e study because of side effect in dapoxetine gre ap.

\section{DISCUSSic}

Befor the pas cecade, the major approach to treating PE wis rioral and psychotherapy, relying on such technic 'es as the 'pause' and 'squeeze' methods (Masters and Joh con, 1970; Kaplan, 1974). However, the application the principles of evidence-based medicine shows that th $\mathrm{ce}$ is little evidence to support the psychological ar proach and behavioral treatment. Dapoxetine gave chronically improved latencies over baseline. However, even at $60 \mathrm{mg}$, the latencies were still $<2 \mathrm{~min}$ in most of the patients. We doubt whether greater than this dose is suitable for large-scale use. Prolongation of the ejaculatory interval within few days of treatment suggests that this acute effect is due to direct blocking of central serotonergic reuptake by dapoxetine. Ejaculation is a reflex comprising different sensory pathways, motor centers, and nerve pathways. This ejaculatory reflex has been shown to be controlled primarily by both serotonin and dopamine (McMahon, 2004). Among the different subtypes of 5-HT receptors, the most important ones on ejaculation are $5-\mathrm{HT}_{1 \mathrm{~A}}, 5-\mathrm{HT}_{1 \mathrm{~B}}$, and $5-\mathrm{HT}_{2 \mathrm{C}}$ receptors (Ahlenius et al, 1981). Because the rapid onset of postponement of ejaculation by some of the SSRIs has a similar time course as their synaptic effect on 5-HT, it is suggested that the effect on ejaculation is mediated by acute enhancement of 5-HT neurotransmission or by differential activation of different 5 -HT receptor populations, notably $5-\mathrm{HT}_{1 \mathrm{~A}}$ and $5-\mathrm{HT}_{2 \mathrm{C}}$ receptors (Szele et al, 1988; Molewijk et al, 1989). Activation of the 5- $\mathrm{HT}_{1 \mathrm{~B}}$ receptor also inhibits 5-HT release and male rat ejaculatory behavior (Hillegaart and Ahlenius, 1998). The total absence of ejaculation delay in men who took nefazodone was attributed to its $5-\mathrm{HT}_{2 \mathrm{C}}$ and $5-\mathrm{HT}_{2 \mathrm{~A}}$ receptor-blocking properties (Waldinger et al, 2001). Serotonin binds to $5-\mathrm{HT}_{2 \mathrm{C}}$ and $5-\mathrm{HT}_{\mathrm{LA}}$ receptors to delay ejaculation. Dapoxetine's mechanism of action is the inhibition of neuronal reuptake of serotonin. It was also shown to bind and inhibit the reuptake transporters of dopamine and norepinephrine (Gengo et al, 2005). Elimination is biphasic, with an initial half-life of approximately $1.4 \mathrm{~h}$ and 
Table 3 Mean IELT, Frequency of Coitus and Mean Intercourse Satisfaction Domain Values of the IIEF

\begin{tabular}{|c|c|c|c|c|c|c|}
\hline & & Baseline & I 2-week & $p$-value & $\begin{array}{l}\text { 3-month } \\
\text { follow-up }\end{array}$ & $p$-value \\
\hline \multicolumn{7}{|l|}{ Group 1} \\
\hline Mean no. of coituses/week & & 1.16 & 2.2 & 0.04 & 1.21 & 0.1 \\
\hline $\begin{array}{l}\text { Mean intercourse satisfaction } \\
\text { domain values of the IIEF }\end{array}$ & & 12 & 16 & 0.04 & 11 & 0.1 \\
\hline \multicolumn{7}{|l|}{ Group 2} \\
\hline Mean IELT (s) & & 31 & 54 & 0.08 & 37 & ง8 \\
\hline Mean no. of coituses/week & & 1.14 & 1.4 & 0.07 & .17 & 0.09 \\
\hline $\begin{array}{l}\text { Mean intercourse satisfaction } \\
\text { domain values of the IIEF }\end{array}$ & & 11 & 10 & 0.09 & & 0.09 \\
\hline & \multicolumn{2}{|c|}{ Satisfied (\%) } & \multicolumn{2}{|c|}{ Moderate satisfier' } & \multicolumn{2}{|c|}{ Dissatisfied (\%) } \\
\hline & Patients & Wives & Pat & & Patients & Wives \\
\hline Baseline & - & - & & & 100 & 94 \\
\hline \multicolumn{7}{|l|}{ Group 1} \\
\hline 12-week & $74 *$ & 69* & & & $12 *$ & $17^{*}$ \\
\hline 3-month follow-up & $3 * *$ & $8 * * *$ & & & $90 * *$ & 7|**⿻丷木 \\
\hline
\end{tabular}

Table 5 Drug-Related Side Effects

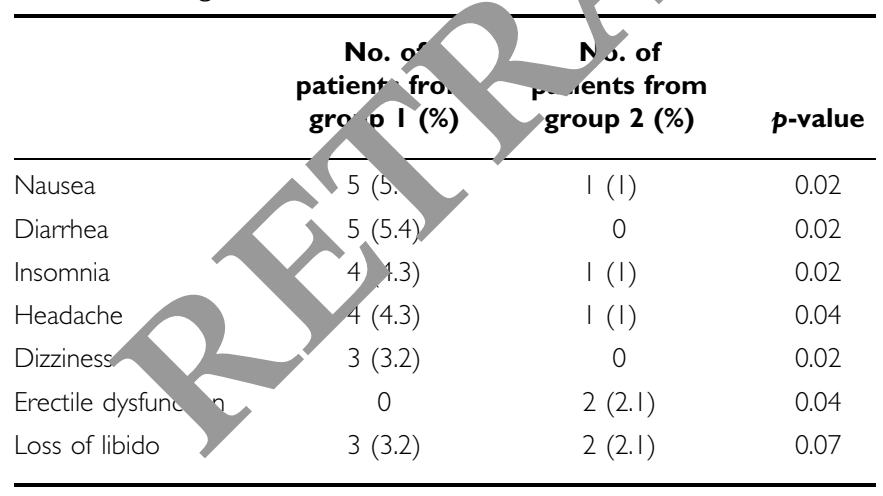

a terminal half-life of approximately $20 \mathrm{~h}$. The pharmacokinetics of dapoxetine metabolites, desmethyldapoxetine, and dapoxetine- $N$-oxide, is unaffected by multiple dosing (Modi et al, 2006).

This study demonstrated that dapoxetine $30 \mathrm{mg}$ twice daily moderately delays ejaculation in men. A 2.9-fold IELT increase is really the minimum that is required for the men with genuine PE. For example, a man with a baseline IELT of $10 \mathrm{~s}$ will get an ejaculation after $30-40 \mathrm{~s}$ when taking this drug. Furthermore, mean weekly intercourse episodes for patients treated with dapoxetine compared to placebo were mildly superior. We also used an inventory for analysis of satisfaction scores for the men or their wives. Satisfaction scores mildly improved with dapoxetine. Although the baseline IIEF erectile function was normal in the two groups, at the end of 12-week treatment period, intercourse satisfaction and overall satisfaction remained low. Men with PE also reported significantly higher problem levels on other aspects of sexual functioning such as difficulty becoming aroused, difficulty discussing sexual problems, satisfaction with sexual intercourse, satisfaction with the sexual relationship, difficulty being able to avoid anxiety about coitus, and problems achieving erections.

Dapoxetine administered increased IELT, as early as after administration of the first dose. The beneficial effects of dapoxetine on outcome measures remain nearly constant after 1-week treatment. In this study, prolong administration of dapoxetine was not associated with further benefit. 
Of the SSRIs, paroxetine, sertraline, fluoxetine, citalopram, and tricyclic antidepressants (clomipramine) have all been shown to be effective in the treatment of PE (Safarinejad and Hosseini, 2006; McMahon, 1998; Manasia et al, 2003; Sae Chul and Kyung, 1998). Waldinger et al (1998b) reported on a study comparing the relative effects of placebo and the SSRI antidepressants: fluoxetine, fluvoxamine, paroxetine, and sertraline on PE. Latencies were increased from a baseline of $18-29 \mathrm{~s}$ on placebo and for the SSRIs, $211,55,476$ and $117 \mathrm{~s}$, respectively. In a study the efficacy and safety of dapoxetine, paroxetine, and placebo were compared for the oral pharmacotherapy of PE (Safarinejad, 2006). Paroxetine provided significantly better results in terms of IELT and intercourse satisfaction $v s$ dapoxetine.

Dapoxetine belongs to the group of SSRIs. The fact that its pharmacokinetic profile is different regarding the duration of half-life and $T_{\max }$ does not mean that its pharmacodynamic properties are different.

The clinical data available on dapoxetine are limited to one phase- 2 and two phase- 3 trials. Hellstrom et al (2004) randomized 166 adult heterosexual men in a multicenter, placebo-controlled, double-blind, 3-period, crossover phase-2 study to either dapoxetine $60 \mathrm{mg}$, dapoxetine $100 \mathrm{mg}$, or placebo. Intention-to-treat analysis demonstrated significant decreases favoring both doses of dapoxetine for increasing IELT compared to placebo $(p<0.0001)$. Nausea was the most commonly reported adverse effect, occurring with greater frequency in the dapoxetine $100-\mathrm{mg}$ group (16.1\%) compared to the $60-\mathrm{mg}$ group $(5.6 \%)$ and placebo grou. $(0.7 \%)$. Pryor et al (2006) conducted two rando 1 ed, double-blind, placebo-controlled, multicenter st ties of identical design in 2614 men diagnosed with $\mathrm{Pr}$ ace ding to DSM-IV definition, one evaluating the $3 \mathrm{mg}$ dos of dapoxetine and the other evaluating the $6 \mathrm{mg}$ ose. Mean IELT at the baseline was 0.90 (SD 0.47) $\mathrm{m} .0 .92(-g) \mathrm{min}$, and $0.91(0.48) \mathrm{min}$, and at study end r bint (week 12 or final visit) was $1.75(2.21) \mathrm{min}$ for placeb $2.78(.48) \mathrm{min}$ for $30 \mathrm{mg}$ dapoxetine, and $3.32(3.68) \mathrm{min}$ fo $n$ dapoxetine. Nausea was the most common in event. Nausea was reported by $20.1 \%$ of patients in be $6 \mathrm{mg}$ group and $8.7 \%$ of patients in the $30 \mathrm{mg}, \mathrm{g}$ up. I LT distribution behaves positively skewed am th mal healthy population and in the individual Ann (Taldinger et al, 2004a). In the above-mentioner. tudies, e authors did not measure geometric mea. It They did not provide confidence intervals of neir fold- 1 , -rease outcomes, which is necessary for a gos. $\mathrm{m}$ r ses ion of the potency of the drug.

The notab fin ings of our study first include the moderat $\mathrm{su}_{\mathrm{f}}$ riorit of dapoxetine over placebo in increasing all or 1 parameters (IELT, IIEF, and mean number of co. s episodes weekly). Second, improvement in the above-n entioned parameters was not observed in the 3-month follow-up after cessation of therapy.

The adverse events of dapoxetine are dose dependent. The most common adverse events associated with dapoxetine are nausea, diarrhea, dizziness, and headache (Hellstrom et al, 2005). Nausea is fairly significant, with an incidence of $20 \%$ reported in patients taking the $60 \mathrm{mg}$ dose of dapoxetine. The rate of nausea in our study was $5.4 \%$. In our study six $(2.8 \%)$ patients discontinued dapoxetine due to adverse events.
It appears dapoxetine does not provide a clear advantage in improving latency time compared with other SSRIs. Questions regarding the true efficacy of the reported studies without a proper statistical analysis are valid. In the current study, we prescribed dapoxetine (without any sponsorship) in a placebo-controlled fashion to men who reported PE but without any known etiologic factor. However, the beneficial effects of dapoxetine were not produced in the 3-month follow-up after cessation of treatment. Clearly, the issue of placebo-controlled trials will remain the ultir ute litmus test of treatment efficacy. However, we presen our tudy as the largest group of men treated and evaluate ollo ing the chronic daily dapoxetine therapy. Medical tre nent in PE needs careful interpretation with spect to design and methodology of the studies (w ding 2,03, 2004). For

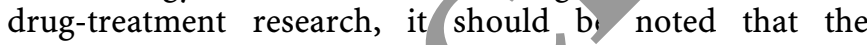
assessment of delay of LEL depen ls on gender (male/ female), absolute IELT $+b_{a}$ r. $c$, tool of assessment (questionnaire, stopy ath), d type of SSRI (Rowland et al, 2001; Perelman $f, 1,2004$, Nearly all of the current pharmacotherapis for 'E are palliative and do not 'treat' or 'cure' the prom actu $4 y$. We need a safe and effective drug laun $\mathrm{d}$ s secifically for the treatment of PE, which induces lon $\mathrm{rm}$ benefit for the patient after it is withd ann.

\section{CONCL ISION}

C $r$ results suggest that dapoxetine is no better than other SS IS in treatment of PE. The real long-term efficiency of apoxetine was not proved after treatment cessation. Opportunities exist for discovering and developing drugs for PE. The positive results from this drug indicate that clinical experiments should continue with various drug regimens and study settings.

\section{ACKNOWLEDGEMENTS}

The investigator is indebted to the patients who participated in this study. We appreciate the encouragement and help provided by coordinators, project managers, and data reviewers. We thank Miss Shiva Safarinejad for her secretarial assistance.

\section{DISCLOSURE/CONFLICT OF INTEREST}

We have no disclosures to report. The author declares that, except for the income received from their primary employer, no financial support or compensation has been received from any individual or corporate entity over the past 3 years for research or professional service, and there are no personal financial holdings that could be perceived as constituting a potential conflict of interest.

\section{REFERENCES}

Ahlenius S, Larsson K, Svensson L, Hjorth S, Carlsson A, Lindberg $\mathrm{P}$ et al (1981). Effects of a new type of 5-HT receptor agonist on male rat sexual behavior. Pharmacol Biochem Behav 15: 785-792.

Baldesarani RJ, Mars E (2003). Fluoxetine and side effects. Arch General Psychiatry 47: 191-192. 
Byers ES, Grenier G (2003). Premature or rapid ejaculation: heterosexual couples' perceptions of men's ejaculatory behavior. Arch Sex Behav 32: 261-270.

Dresser M, Lindert K, Lin D, Gidwani S, Gupta SK, Modi NB (2004). Pharmacokinetics of single and multiple escalating doses of dapoxetine in healthy volunteers [abstract]. Clin Pharmacol Ther 75: 113.

Feret B (2005). Focus on dapoxetine: a novel, fast-acting serotonin reuptake inhibitor. Formulary 40: 227-230.

Fisher E (1986). Common sexual problems in general practice. Aust Fam Physician 15: 43-47.

Fleiss J (1986). The Design and Analysis of Clinical Experiments. John Wiley \& Sons Inc.: New York, NY, pp 49-51.

Frink MC, Hennies HH, Englberger W, Haurand M, Wilffert B (1996). Influence of tramadol on neurotransmitter systems of the rat brain. Arzneimittelforschung 46: 1029-1036.

Gengo PJ, View M, Giuliano F, McKenna KE, Chester A, Lovenberg $\mathrm{T}$ (2005). Monoaminergic transport binding and inhibition profile of dapoxetine, a medication for the treatment of premature ejaculation. J Urol 173(Suppl): 239. (abstract 878).

Hellstrom WJ, Althof S, Gittelman M, Steidle C, Ho KF, Kell S et al (2005). Dapoxetine for the treatment of men with premature ejaculation (PE): dose-finding analysis. J Urol 173(Suppl): 238 (abstract 877).

Hellstrom W, Gittelman M, Althof S, Ho KF, Kell S (2004). Dapoxetine $\mathrm{HCl}$ for the treatment of premature ejaculation: a phase II, randomized, double-blind, placebo-controlled study. J Sex Med 1(Suppl): 59. (abstract 097).

Hillegaart V, Ahlenius S (1998). Facilitation and inhibition of male rat ejaculatory behaviour by the respective 5-HT1A and 5-HT1B receptor agonists. Brit J Pharmacol 125: 1733-1743.

Kaplan HS (1974). The New Sex Therapy: Active Treatment of Sexual Dysfunctions. Brunner/Maazel: New York.

Kim SW, Paick JS (1999). Short-term analysis of the effects of needed use of sertraline at $5 \mathrm{pm}$ for the treatment of premat ejaculation. Urology 54: 544-547.

Laumann EO, Paik A, Rosen RC (1999). Sexual dysfuncti n in the United States: prevalence and predictors. JAMA 281 5 J 544.

Manasia P, Pomerol J, Ribe N, Gutierrez del Pozo R, Acuver cia $\mathrm{J}$ (2003). Comparison of the efficacy and safet/of 90 vs $20 \mathrm{ng}$ fluoxetine in the treatment of premature ejact ation. J Urol 170: 164-165.

Masters WH, Johnson VE (1970). Hur an Sexu. adequacy. Little, Brown: Boston, pp 92-142.

McMahon CG (1998). Treatment of pren at are -jaculation with sertraline hydrochloride: a placebo controlled crossover study. J Urol 159: 35-1 338.

McMahon CG (2004). Phar aco lcai weatment of ejaculatory disorders. J Sex Med (S rpl 1): 1, '1.

Modi NB, Dresser MJ, Im M, Lin D, Desai D, Gupta S (2006). Single- and mul ale-dose barmacokinetics of dapoxetine hydrochloride, no el agen - for the treatment of premature ejaculation. JCa Prarm ' $\mathrm{col}$ 46: 301-309.

Molewijk $\mathrm{H}^{\mathrm{F}}$ van a $\mathrm{H}$ yden JAM, Olivier B (1989). Lower lip retracti $n$ is selecti - mediated by activation of the 5-HT1A recepio rosci 214(Suppl 2): 121.

Perelman M. McMahon CG, Barada JH (2004). Evaluation and treatment of ne ejaculatory disorders. In: Lue T (ed). Atlas of Male Sexual Dysfunction. Current Medicine, Inc.: Philadelphia, PA. pp 127-157.

Pryor JL, Althof SE, Steidle C, Rosen RC, Hellstrom WJ, Shabsigh $\mathrm{R}$, Dapoxetine Study Group et al (2006). Efficacy and tolerability of dapoxetine in treatment of premature ejaculation: an integrated analysis of two double-blind, randomised controlled trials. Lancet 9: 929-937.

Remy L (1986). The effect of selective 5HT reuptake inhibitors on 5 -methoxy- $N, N$-dimethyltriptamine induced ejaculation in the rat. Br J Pharmacol 87: 639-648.

Rosen RC, Riley A, Wagner G, Osterloh IH, Kirkpatrick J, Mishra A (1997). The International Index of Erectile Function (IIEF): a multidimensional scale for assessment of erectile dysfunction. Urology 49: 822-830.

Rowland DL, Cooper SE, Schneider M (2001). Defining prmature ejaculation for experimental and clinical investigati ns. A ch Sex Behav 30: 235-253.

Sae Chul K, Kyung S (1998). Efficacy and safety of $\mathrm{h} x$ ane, sertraline and clomipramine in patients wi vrematu re-jaculation: a double-blind, placebo controlled st 'dy. $\mathrm{ol}^{\prime} 5^{\prime}$. 425-427.

Safarinejad MR (2006). Comparison of $c$ apoxetine aroxetine in patients with premature ejaculatior a double-blind, placebocontrolled, fixed-dose, randomi $\mathrm{ed} \mathrm{s}^{\mathrm{d}} \mathrm{v}$. Cli Neuropharmacol 29: $243-252$.

Safarinejad MR, Hosseini $Y$ (20u Safety and efficacy of citalopram in the tre $\mu$ nt of emature ejaculation: a double-blind placebo-cuntro 4 , fixed dose, randomized study. Int J Impot Res 18. -169.

Spector IP, Carey TP (1 90). Incidence and prevalence of sexual dysfunctions. A $\mathrm{c}_{1}$ ar efw the empirical literature. Arch Sex Behav 19: 389-4

Symonds T, Min D Hart K, Althof S (2003). How does premature jarain on impact a man's life? J Sex Marital Ther 29: 361-370.

Sze ${ }^{1-} \mathrm{G}$, Murp DL, Garrick NA (1988). Effects of fenfluramine, $\mathrm{m}-\mathrm{Ch}_{4}$ rophenylpiperazine and other serotonin-related agonists and a agonists on penile erections in non-human primates. L S / 43: 1297-1303.

Walc iger MD (2003). Towards evidence-based drug treatment esearch on premature ejaculation: a critical evaluation of methodology. Int J Impot Res 15: 309-313.

Waldinger MD (2004). Life-long premature ejaculation: from authority based to evidence based medicine. $\mathrm{Br} J$ Urol, Int Update Series 93: 201-207.

Waldinger MD, Berendsen HHG, Blok BFM, Olivier B, Holstege G (1998a). Premature ejaculation and serotonergic antidepressantinduced delayed ejaculation: the involvement of the serotonergic system. Behav Brain Res 92: 111-118.

Waldinger MD, Hengeveld MW, Zwinderman AH (1994). Paroxetine treatment of premature ejaculation: a double-blind, randomised, placebo-controlled study. Am J Psychiatry 151: 1377-1379.

Waldinger MD, Hengeveld MW, Zwinderman AH, Olivier B (1998b). Effect of SSRI antidepressants on ejaculation: a double-blind, randomised, placebo controlled study with fluoxetine, fluvoxamine, paroxetine and sertraline. J Clin Psychopharm 18: 274-281.

Waldinger MD, Zwinderman AH, Olivier B (2001). Antidepressants and ejaculation: a double-blind, randomized, placebo-controlled, fixed-dose study with paroxetine, sertraline, and nefazodone. J Clin Psychopharm 21: 293-297.

Waldinger MD, Zwinderman AH, Schweitzer DH, Olivier B (2004a). Relevance of methodological design for the interpretation of efficacy of drug treatment of premature ejaculation: a systematic review and meta-analysis. Int $J$ Impot Res 16: 369-381. 